\title{
PREDICTIVE FACTORS FOR COMPLETE AND INCOMPLETE EVALUATION OF SMALL INTESTINE BY ENDOSCOPIC CAPSULE
}

\author{
Fatores preditivos para avaliação completa e incompleta do intestino delgado pela cápsula endoscópica \\ Andréia Sopran SCOPEL ${ }^{1,2}$, Fernando Issamu TABUSHI ${ }^{1 \oplus}$, Luis Fernando Kubrusly ${ }^{1 \oplus}$, Paula Bechara \\ POLETTI $^{1,2 \oplus}$, Artur Adolfo PARADA ${ }^{1,2 \odot}$, Milena Perez MOREIRA ${ }^{1,2 \odot}$, Thiago Festa SECCHI ${ }^{2 \odot}$
}

\begin{abstract}
Background: The small-bowel is the most difficult segment to be visualized by traditional endoscopic methods. The need for its exploration led to the development of capsule endoscopy. The percentage of the complete examination varies and still remains uncertain the factors that influence the complete and incomplete examination. Aim: Evaluate the factors that interfere with the completeness of the endoscopic evaluation by the capsule. Methods: A prospective study in which were included 939 patients divided into two groups: complete group (CG) and incomplete group (IG). The studied variables that could interfere were: age, gender, comorbidities, diagnosis of Crohn's disease, previous abdominal surgery, inadequate preparation to compare the groups reached and did not reach the cecum. Results: Of the 939 patients included 879 (93.3\%) reached the cecum (CG) and 63 (6.7\%) IG no. The IG was composed of 29 (46.0\%) men and 34 (54.0\%) women with a mean age of 49.7 years; comorbidities this group accounted for $46 \%$ of which $15.9 \%$ was Crohn's disease, previous abdominal surgery $22.2 \%$ and $17.5 \%$ inadequate preparation. Conclusion: Factors associated with complete or incomplete outcome of the examination with capsule endoscopy were: associated comorbidities, Crohn's disease, previous abdominal surgery and inadequate preparation.

HEADINGS - Capsule endoscopy. Small intestine. Crohn disease. Comorbidity.
\end{abstract}

RESUMO - Racional: O intestino delgado é segmento de maior dificuldade na visualização pelos métodos endoscópicos tradicionais. A necessidade de explorá-lo levou ao desenvolvimento da cápsula endoscópica. A porcentagem do exame completo por ela varia e falta identificar fatores que influenciam o exame completo e incompleto. Objetivo: Avaliar os fatores que interfiram na completude do estudo endoscópico pela cápsula. Método: Estudo prospectivo onde foram incluídos 939 pacientes divididos em dois grupos: grupo completo (GC) e grupo incompleto $(\mathrm{Gl})$. As variáveis analisadas que pudessem interferir foram: idade, gênero, comorbidades associadas, diagnóstico de doença de Crohn, operações abdominais prévias, preparo inadequado para comparar os grupos que atingiram e não atingiram o ceco. Resultados: Dos 939 pacientes incluídos 879 (93,3\%) atingiram o ceco (GC) e $63(6,7 \%) \mathrm{Gl}$ não. O Gl era composto por 29 (46,0\%) homens e $34(54,0 \%)$ mulheres com idade média de 49,7 anos; as comorbidades deste grupo corresponderam a $46 \%$, das quais $15,9 \%$ era doença de Crohn, $22,2 \%$ operação abdominal prévia e 17,5\% preparo inadequado. Conclusão: Os fatores associados ao desfecho completo ou incompleto do exame com a cápsula endoscópica foram: comorbidades associadas, doença de Crohn, operação abdominal prévia e preparo inadequado.

DESCRITORES - Cápsula endoscópica. Intestino delgado. Doença de Crohn. Comorbidade.

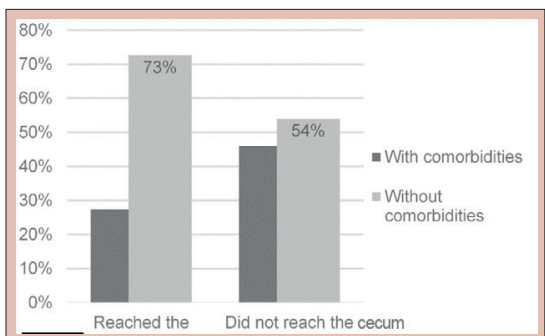

Results of CE between groups with or without associated comorbidities

\section{Central message}

The small intestine is the most difficult segment to view using traditional endoscopic methods. The need for its exploration led to the development of the endoscopic capsule.

\begin{tabular}{|l|}
\hline Perspective \\
The endoscopic examination of the small intestine is \\
limited by its length. The need to explore this relatively \\
inaccessible segment led to the development of the \\
endoscopic capsule. The study of the small intestine \\
has improved significantly with the introduction \\
of it, which has become the standard method for \\
investigating certain diseases.
\end{tabular}

From the ${ }^{1}$ Programa de Pós-Graduação em Princípios da Cirurgia, Faculdade Evangélica Mackenzie do Paraná/Instituto de Pesquisas Médicas, Curitiba, PR, Brasil; 2Serviço de Endoscopia Digestiva, Centro de Diagnóstico e Terapêutica Endoscópica de São Paulo, Hospital 9 de Julho, São Paulo, SP, Brasil ('Postgraduate Program in Principles of Surgery, Mackenzie Evangelical Faculty of Paraná/Medical Research Institute, Curitiba, PR, Brazil; 2Gastrointestinal Endoscopy Senvice, 9 of July Hospital, São Paulo, SP, Brazil)

How to cite this article: Scopel AS, Tabushi Fl, Kubrusly LF, Poletti PB, Parada AA, Moreira MP, Secchi TF. Predictive factors for complete and incomplete evaluation of small intestine by endoscopic capsule. ABCD Arq Bras Cir Dig. 2020;33(2):e1532. DOI: /10.1590/0102-672020190001e1532

\section{Correspondence:}

Andréia Sopran Scopel

E-mail: andreia.scopel@hotmail.com
Financial source: This study was financed in part by the Coordenação de Aperfeiçoamento de Pessoal de Nível Superior - Brasil (CAPES) - Finance Code 001

Conflict of interest: none

Received for publication: 20/04/2020

Accepted for publication: 25/06/2020 


\section{INTRODUCTION}

$\mathrm{T}$ he small bowel is the gastrointestinal tract site that has the greatest difficulty to be visualized by endoscopic traditional methods and, in it, endoscopy has limited access due to its length and the distance of accessible natural orifices $^{8}$. The need to explore this relatively inaccessible segment led to the development of capsule endoscopy (CE) ${ }^{12}$. The study of the small intestine has improved significantly with the introduction of this device that has become standard method in the investigation of this segment ${ }^{15,24}$.

Currently, there are many indications to its use. Mainly, is indicated for gastrointestinal obscure bleeding, inflammatory bowel disease, celiac disease and small intestine cancer ${ }^{12,15,24}$.

Small bowel comprises approximately $75 \%$ of the obscure gastrointestinal bleeding, defined as digestive, persistent or recurrent in origin, and no recognized after colonoscopy ${ }^{14,24,26}$ and upper endoscopy. The obscure bleeding represents 3-5\% of cases, is expensive and life-threatening $2,3,17,22$.

In obscure bleeding, or when other endoscopic examinations wereinconclusive, further investigation with the CE is recommended ${ }^{18,20}$. It was approved in 2001 by the Food and Drug Administration $(F D A)^{12}$ in the USA and allows visualization of the mucosa of the

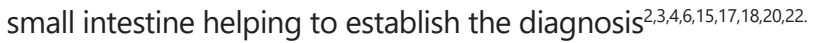

The percentage of complete examination by the CE varies and studies seek to identify factors that may influence lack of completeness that can limit its use. There are few publications on this topic in the international literature.

The objective of this study was to evaluate the factors that prevented the completion of the endoscopic study of the small intestine by the capsule.

\section{METHODS}

This study was approved by the Research Ethics Committee of the Mackenzie Evangelical Faculty of Paraná, Curitiba, PR, Brazil and all patients signed informed consent prior to the examination. The design was prospective and observational.

Were included 939 patientswho underwentCE in Gastrointestinal Endoscopy Department of the July 9 Hospital, São Paulo, SP, Brazil. The following variables were analyzed: gender, age, comorbidities, presence of Crohn's disease, previous abdominal surgery, the inadequate preparation and the reach of the CE to the cecum in the test recording time. The life span of the batteries to keep the recording is about $8 \mathrm{~h}$. The exam preparation was considered inadequate in the presence of residues or foodborne stasis which interfered with the proper mucosal evaluation. Data were recorded on a prospective spreadsheet. The capsules used were Mirocam ${ }^{\oplus}$ Given $^{\circledR}$ and MA2 and SB2. All examinations were evaluated by two of the authors of this paper (PBP and TFS).

The preparation was the same for all patients, which consisted on the suspension of ferrous sulfate three days before the exam, and in the previous day, fed only with soft diet without waste or with clear liquids, administration of four bisacodyl tablets after lunch, intake of $1000 \mathrm{ml}$ of water at $21 \mathrm{~h}$ with 100 drops of dimethicone, fasting of $10 \mathrm{~h}$ and $1 \mathrm{~h}$ before the procedure another ingestion of $1000 \mathrm{ml}$ of water with 100 drops of dimethicone.

The independent variable was the capability of capsule endoscopy to reach the cecum. The images were captured by a portable recorder set at special abdominal belt for $8 \mathrm{~h}$ and transferred to the computer that processed the film with the help of specific software.

The patients were divided into two groups: complete study (CG) and incomplete (IG), which have or have not reached the cecum in the recording time.

Data were entered in Excel 2010 spreadsheets for Windows and statistical analyzes used the $R$ version 3.0.2 program.

\section{Statistical analysis}

It was made in a descriptive way through the mean, median, minimum and maximum values, standard deviation, absolute and relative frequencies (percentage), and graphics-dimensional dispersion and bars. The inferential analyzes performed in order to confirm or refute evidence found in the descriptive analysis were Chi-square or exact Fisher test ${ }^{1}$ when comparing the groups that reached or did not reach the cecum during recording time, by gender, presence of associated comorbidities, Crohn's disease, previous abdominal surgery and inadequate preparation. Mann-Whitney ${ }^{19}$ was used when comparing the groups that reached and did not reach the cecum by age. The alpha level of significance was $5 \%$.

\section{RESULTS}

Of the total sample of 939 patients, 462 (49.3\%) were men and $476(50.7 \%)$ women. The mean age was $53.2 \pm 19.6$ years (595). In the CG, 433 (49.5\%) were men and 442 (50.5\%) women and in the IG 29 (46\%) men and 34 (54\%) women with $p=0.596$. The mean age in the CG was 53.5 years and in the IG 49.7 years with $p=0.170$ (Figure 1). From total, 268 (28.6\%) patients had associated comorbidities, with Crohn's disease in 67 (7.1\%) and previous abdominal surgery 122 (13\%, Figures $2 \mathrm{~A}, 2 \mathrm{~B}$ and $2 \mathrm{C})$.

Among all cases, 879 (93.3\%) reached the cecum and 63 (6.7\%) did not (Figure 2D). Associated comorbidities were present in $239(27.4 \%)$ in the CG and $29(46 \%)$ in the IG $(p=0.002)$. In CG 57 (6.5\%) they had Crohn's disease and in IG 10 (15.9\%, p=0.011). Previous abdominal surgery had been performed in 108 (12.3\%) in the $C G$ and in $14(22.2 \%, p=0.024)$ in the IG. Of the 63 patients who failed to reach the cecum, 11 (17.5\%) had inadequate preparation $(p<0.001)$. In these, the causes of inadequate preparation were subdivided (Figure 2E), which were attributed to: 1) changes in the mucosa $(n=9,81.8 \%) ; 2)$ age over 60 years $(9.1 \%)$; and 3 ) only to inadequate preparation without other associated factors $(9.1 \%$,).

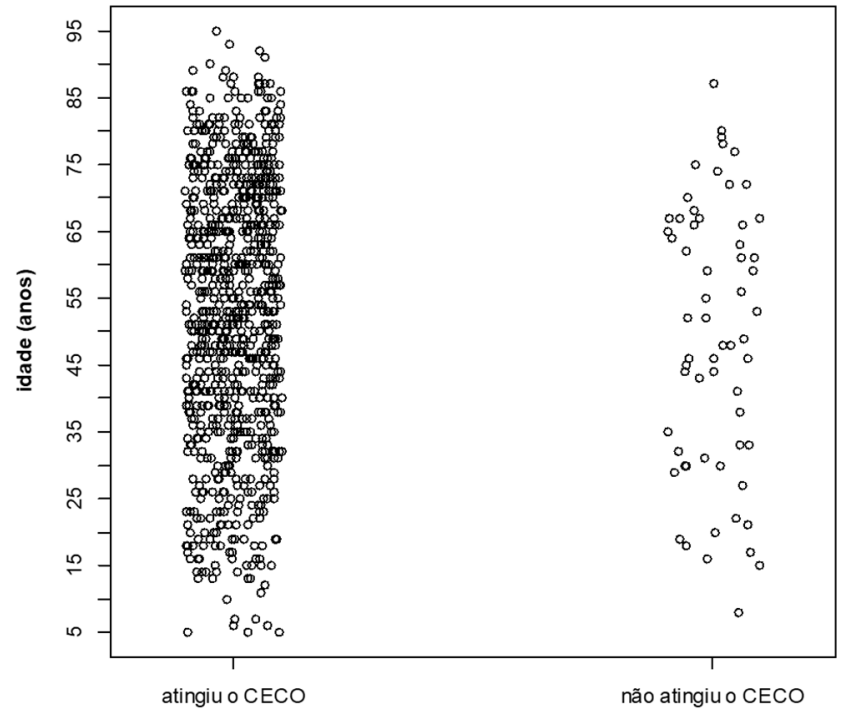

FIGURE 1 - One-dimensional dispersion diagram of the age (years) of patients according to CE results

The group of 875 patients who had a complete CE study (CG) was formed by 433 (49.5\%) men and 442 (50.5\%) women. Their average age was $53.5 \pm 19.6$ years (5-95). Associated comorbidity was present in $27.4 \%(n=239)$; Crohn's disease in $6.5 \%(n=57)$ and previous abdominal operation $12.3 \%(n=108)$. 


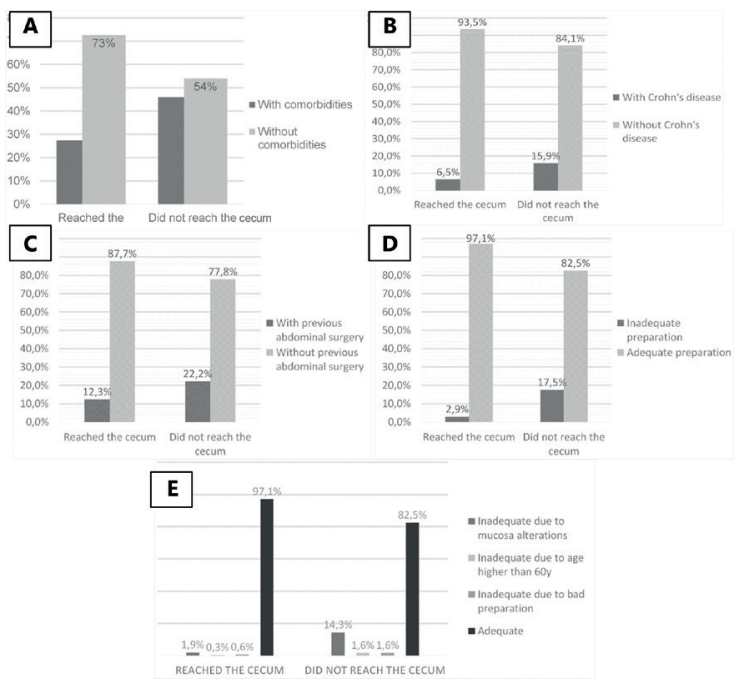

FIGURE 2 - Results of CE between groups: A) with or without associated comorbidities; B) presence of Crohn's disease; C) with previous abdominal operation; D) state of preparation; E) reasons why the preparation was inadequate, according to cases that reached or did not reach the cecum

The inferential results confirmed the same gender $(p=0.596)$ and age $(p=0.170)$ profile, regardless of whether or not reached the cecum. The same behavior was not observed when comparing the presence of associated comorbidity $(p=0.002)$, Crohn's disease $(p=0.011)$ and previous abdominal surgery $(p=0.024)$; so, patients who have reached the cecum had fewer comorbidities, Crohn's disease and previous abdominal surgery.

\section{DISCUSSION}

Several authors have studied the complete transit of the CE achieving different percentages, but very close. According to Rahmi Gabriel et al. ${ }^{16}$ in long-term multicenter prospective study, the complete transit of the CE through the small intestine was achieved in 91.8\%; Vlachogiannakos et al. ${ }^{22}$ showed $87 \%$; and Hoedemaker et al. ${ }^{9} 81.8 \%$. In a review involving 22,840 procedures, the percentage was $85.4 \%{ }^{11}$. In the present study the full evaluation was possible in $93.3 \%$, showing higher rate compared to most studies. Authors report incomplete rates ranging from $0-50 \%$, which in these cases is unfavorable to the method for potential diagnosis $\operatorname{loss}^{25}$.

Retrospective studies have identified factors that may be predictive of incomplete examination; among them are mentioned bedridden patients, previous abdominal surgery and bowel inadequate preparation ${ }^{25}$. In this study, it was demonstrated that gender and age were not significant factors for both groups, which is also shown by other authors ${ }^{13,21,23,25}$.

The variables analyzed here - comorbidities, diagnosis of Crohn's disease, previous abdominal surgery and inadequate preparation - were factors that showed be impeditive to complete examination.

Associated comorbidity $(p=0.002)$ had significant difference between the two groups, which is corroborated by studies that add chronic diseases in hospital ${ }^{5,13,25}$ as a factor that contributes to the incomplete study.

Chronic diseases are associated with prolonged CE retention in the stomach due to longer gastric emptying time, which results in inadequate time for the complete evaluation of the small intestine, since the battery life is about $8 h^{5,7,21}$.

Regarding Crohn's disease, it is considered a significant factor for incomplete study $(p=0.011)$. This has proven to be an important risk factor for the retention of $\mathrm{CE}^{7,10}$. Its diagnosis requires a combination of clinical, endoscopic and histological findings.
Most image studies offer low sensitivity for early identification of the disease and, furthermore, upper gastrointestinal endoscopy and colonoscopy does not allow complete examination of the bowel.

The CE has a higher sensitivity in the identification of mucosal changes; therefore, it has valuable role in bowel evaluation as a whole, and especially in those with known or suspected Crohn's ${ }^{10}$.

Studies associated previous history of intestinal obstruction as a predictive factor for the exam be incomplete ${ }^{10,25}$ circumstance more commonly found in patients with Crohn's disease ${ }^{7,10}$.

The presence of previous abdominal surgery was significantly associated with incomplete study $(p=0.024)$; this fact has been reported by other authors with very close ratios to herein ${ }^{10,11,13,21,25}$.

The inadequate preparation was significant in IG $(p<0.001)$. Most IG patients (81.8\%) presented mucosal changes such as edema, hyperemia, changes of the villi, fibrosis, stenosis, scar retractions, deformities, tacks, ulcers or diverticula. This suggests that the existence of chronic diseases, inflammatory bowel disease, tumor or obstruction can justify. Age as a possible factor to influence the proper preparation could be attributed to delayed gastric emptying; but, in this study, it was not the main cause (9.1\%), as the same rate was found for the presence of residues or stasis, with no apparent cause.

The poor bowel preparation was also a significant factor for incomplete examination in other studies $9,10,13,21,25$

\section{CONCLUSION}

Factors associated with complete or incomplete outcome of the examination with capsule endoscopy were: associated comorbidities, Crohn's disease, previous abdominal surgery and inadequate preparation.

\section{REFERENCES}

1. AgrestiA.Categorical dataanalysis.NewYork:WileyInterscience, $1990,558 \mathrm{p}$

2. Ali A, Santisi JM, Vargo J. Video capsule endoscopy: a voyage beyond the end of the scope. Cleve Clin J Med. 2004 May;71(5):415-25.

3. American Society for Gastrointestinal. Endoscopy (ASGE). The role of endoscopy in the management of obscure GI bleeding. Gastrointestinal Endoscopy. 2010. 72( 3): 471 - 479.

4. Banić M, Babić Z, Kujundzić M, Petricusić L, Urek-Crncević M, Grgurević l, Kardum D, Bokun T. [Video capsule endoscopy--preliminary experience in university hospital setting]. Acta Med Croatica.2009 May;63(2):159-64.

5. Ben-Soussan E, Savoye G, Antonietti M, Ramirez S, Lerebours E, Ducrotté $P$. Factors that affect gastric passage of video capsule. Gastrointest Endosc. 2005:62:785-790.

6. Carol E.Semrad Small Bowel enteroscopy: Territory conquered, future horizons. Disclosures. Curr Opin Gastroenterol. 2009; 25(2):110-115.

7. Cheon JH, Kim YS, Lee IS, et al. Can we predict spontaneous capsule passage after retention? A nationwide study to evaluate the incidence and clinical outcomes of capsule retention. Endoscopy 2007;39:1046-52.

8. da Costa RD, Kemp R, dos Santos JS, DAPD, Ardengh JC, Ribas-Filho JM, Ribas CAPM. The role of conventional echoendoscopy (EUS) in therapeutic decisions in patients with neuroendocrine gastrointestinal tumors. ABCD Arq Bras Cir Dig. 2020;33(2):e1512. DOI: /10.1590/0102$672020190001 \mathrm{e} 1512$

9. Hoedemaker RA, Westerhof J, Weersma RK, Koornstra JJ. Non-smallbowel abnormalities identified during small bowel capsule endoscopy. World J Gastroenterol 2014; 20(14): 4025-4029.

10. Kav T, Bayraktar Y. Five years' experience with capsule endoscopy in a single center. World J Gastroenterol 2009 April 28; 15(16): 1934-1942.

11. Kav T, Bayraktar Y. Five years' experience with capsule endoscopy in a single center. World J Gastroenterol 2009 April 28; 15(16): 1934-1942.

12. Mishkin DS, Chuttani R, Croffie J, DiSario J, Liu J, et al. ASGE Technology Status Evaluation Report: wireless capsule endoscopy. Gastrointestinal Endoscopy. 2006 63(4): 539- 545.

13. Mitchell M Lee et al. Factors associated with incomplete small bowel capsule endoscopy studies. World J Gastroenterol. 2010 Nov 14; 16(42): 5329-5333.

14. Ohmiya N1, Nakagawa Y, Nagasaka M, Tahara T, Shibata T, Nakamura M, Hirooka Y, Goto H, Hirata I. Obscure gastrointestinal bleeding: diagnosis and treatment. Dig Endosc. 2015 Mar; 27(3):285-94. 
15. Pennazio M, Spada C, Eliakim R et al. Small-bowel capsule endoscopy and device-assisted enteroscopy for diagnosis and treatment of small bowel disorders: European Society of Gastrointestinal Endoscopy (ESGE) Clinical Guideline. Endoscopy 2015; 47: 352-376.

16. RahmiGabriel etal. Long-term follow-up of patients undergoing capsule and double-balloon enteroscopy for identification and treatment of small-bowelvascularlesions:aprospective, multicenterstudy. Endoscopy 2014; 46: 591-597.

17. Segarajasingam DS, Hanley SC, Barkun AN, Waschke KA, Burtin P, Parent J, Mayrand S, Fallone CA, Jobin G, Seidman EG, Martel M. Randomized controlled trial comparing outcomes of video capsule endoscopy with pushenteroscopyinobscuregastrointestinalbleeding. CanJGastroenterol Hepatol. 2015 Mar;29(2):85-90.

18. Seong-Joon Koh, Jong Pil Im, Ji Won Kim, Byeong Gwan Kim, Kook Lae Lee, Sang Gyun Kim, Joo Sung Kim, Hyun Chae Jung. Long-term outcome in patients with obscure gastrointestinal bleeding after negative capsule endoscopy. World J Gastroenterol 2013 March 14; 19(10): 1632-1638.

19. SIEGEL, S. Estatística não-paramétrica para ciências do comportamento. 2. ed. Porto Alegre: Artmed, 2006, 448p

20. TanW, GeZZ, GaoYJ, LiXB, DaiJ,FuSW,ZhangY,XueHB,ZhaoYJ.Long-term outcome in patients with obscure gastrointestinal bleeding after capsule endoscopy. J Dig Dis. 2015 Mar;16(3):125-34.
21. Triantafyllou K, Kalantzis C, Papadopoulos AA, Apostolopoulos P, Rokkas T, Kalantzis N, Ladas SD. Video-capsule endoscopy gastric and small bowel transit time and completeness of the examination in patients with diabetes mellitus. Dig Liver Dis. 2007;39:575-580. [PubMed]

22. VlachogiannakosJ, PapaxoinisK, ViazisN, KegioglouA, BinasI,Karamanolis $D$, Ladas SD. Bleeding lesions within reach of conventional endoscopy in capsule endoscopy examinations for obscure gastrointestinal bleeding: is repeating endoscopy economically feasible? Dig Dis Sci 2011; 56: 1763-1768.

23. W. Complete small-bowel transit in patients undergoing capsule endoscopy:determining factorsand improvementwith metoclopramide. Gastrointest Endosc 2005;61:80-5.

24. Westerhof J, Koornstra JJ, Weersma RK. Capsule endoscopy: a review from the clinician's perspectives. Minerva Gastroenterol Dietol. 2008 Jun;54(2):189-207.

25. Westerhof J, Weersma RK, Koornstra JJ. Risk factors for incomplete small-bowel capsule endoscopy. Gastrointest Endosc. 2009; 69:74-80.

26. Yang Won Min, Jin Su Kim, Seong Woo Jeon et al. Long-term outcome of capsule endoscopy in obscure gastrointestinal bleeding: a nationwide analysis. Endoscopy 2014; 46: 59-65 